\title{
Is Culture the Cause? Choices, Expectations, and Electoral Politics in Solomon Islands and Papua New Guinea

\author{
Terence Wood
}

\begin{abstract}
Research on Solomon Islands and Papua New Guinea typically offers one of two explanations for the choices voters make, and the way these choices contribute to those countries' poor political governance. The first explanation focuses on culture's influence on the expectations that voters hold of politicians, contending that the Big Man style of local leadership traditionally found in both countries has shaped voter expectations in ways that cause voters to demand local or personal benefits from MPs rather than good national governance. The second explanation hinges on rational choice models of voter behaviour and does not include culture in its list of explanatory variables. In this paper I argue that neither explanation fits well with key features of these countries' politics. Drawing on quantitative and qualitative data I show that, while voters are broadly rational and can readily distinguish modern politics from traditional leadership, culture still matters. In particular, informal institutions, associated with the countries' cultural contexts, influence voter behaviour and electoral collective action, and through this political governance.
\end{abstract}

Keywords: political culture, rational choice, Solomon Islands, Papua New Guinea, electoral politics

DOI: http://dx.doi.org/10.5509/201689131

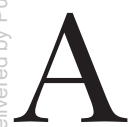

lthough they are democracies, the Melanesian states of Solomon Islands and Papua New Guinea (PNG) are poorly governed by their elected political leaders. To date, academic work seeking to explain voter behaviour and the link between voter behaviour and poor political governance has offered two competing explanations of the problems and phenomena observed. In the first, culture is claimed to be the cause. Specifically, scholars making this type of argument contend that voters see Members of Parliament (MPs) as the modern equivalents of traditional Big Men (community leaders) and, as a result of such culturally grounded

TERENCE Wood is a research fellow at the Australian National University's Development Policy Centre. Email: terence.wood@anu.edu.au 
perceptions, expect of MPs the sorts of private goods and club goods that traditional Big Men delivered, as opposed to the sorts of public goods and services necessary for a well-governed nation state. In explanations of the second sort, the countries' cultural context is afforded only a marginal role, if any at all. Instead, these explanations are based around rational voters, whose interactions with, and expectations of, politicians are shaped by strategic calculations and the material and political circumstances voters find themselves in. In this type of explanation, rational voting leads to poor political governance as a consequence of collective action problems, which turn individually sensible choices into sub-optimal collective outcomes.

In this paper I examine both types of explanation, and argue neither is wholly able to explain important aspects of voter behaviour. By highlighting similarities between voter behaviour in Solomon Islands and PNG and other countries that do not have recent histories of Big Man-style community leadership, I show the cultural expectations argument is not necessary to explain voter behaviour in the two countries. Then, by detailing the many untraditional aspects of voter choice in Solomon Islands and PNG, I show the cultural expectations explanation is not sufficient as an explanation of voter behaviour. Following this, I draw on two central features of the countries' electoral outcomes-candidate numbers and the fate of women candidatesas well as the individual case of West 'Are Are constituency in Solomon Islands, to highlight the deficiencies of the rational choice argument.

In the final section of this paper I demonstrate that an element of culture does play a role in shaping the choices voters make in Solomon Islands and PNG and, through this, the quality of political governance in the two countries. However, culture's importance is not manifest through the expectations voters hold of leaders, but rather is mediated through a particular aspect of culture: informal institutions. These institutions constrain the choices of voters, limit some candidates' access to resources and powerful supporters, and influence the possibility of certain forms of electoral collective action.

In using the term "institution" I follow North in defining institutions as rules not entities. ${ }^{1}$ In using the term "informal institution" I have followed Helmke and Levitsky in defining informal institutions as "socially shared rules, usually unwritten that are created, communicated and enforced outside of officially sanctioned channels." In the case of my study, these rules vary from comparatively subtle gender norms to much more tangible strictures of obedience found within some clans, communities, and churches. However, these rules have a central element of informality in common: they are social rules, not

Douglass North, Institutions, Institutional Change and Economic Performance (Cambridge: Cambridge University Press, 1990).

2 Gretchen Helmke and Steven Levitsky, "Informal Institutions and Comparative Politics: A Research Agenda,” Perspectives on Politics 2, no. 4 (2004): 725-740, 727. 
government rules, nor state-sanctioned rules such as the written constitutions of businesses or similar organizations. While the definition I am using pertains to a particular aspect of culture-socially shared rules-I am not using "informal institutions" and "culture" as synonyms. Informal institutions are only a subset of culture, and much that might be associated with culture, such as shared tastes or understandings, does not directly involve rules.

In advancing my argument about the influence of informal institutions on voter behaviour I am not seeking to explain every aspect of politics in Solomon Islands and PNG. I am not seeking, for example, to offer an explanation of the formation of governing coalitions, or to explain all the machinations of candidates' campaign strategies. Rather, my contribution is to offer a distinct and empirically grounded alternative to the two main existing approaches to understanding voter behaviour in the two countries.

In addition to secondary sources, my analysis draws on the following primary data: constituency-level Solomon Islands election results from 1980 to 2014; polling station election results for the 2006 and 2010 elections in Solomon Islands; MP bio-data for the two countries (compiled with a fellow researcher); constituency-level PNG election results for elections from 1977 to 2002 (2002 being the most recent election full results are available for); and qualitative data from interviews with voters and political actors in Solomon Islands. ${ }^{3}$ These interviews were conducted as part of a larger project on electoral politics in Solomon Islands (involving a total of 250 interviews in 2011 and 2012). Although I interviewed people from all but one of Solomon Islands' constituencies, the bulk of my interviewees came from six constituencies where I conducted extensive fieldwork. These constituencies were selected to provide variation in population, urbanization, and location. Interviewees included politicians, former politicians, candidates, community leaders, and voters. Voters were normally interviewed in their villages. Because members of Solomon Islands' political elite typically live in Honiara, many of my elite interviews were conducted there.

In the analysis that follows, I draw upon the quantitative datasets to provide context, and evidence showing that Solomon Islands and PNG do not fit with existing explanations of electoral politics. With regards to my qualitative data, needless to say, not all of it can be presented here; rather, I focus on specific interviews relevant to cases of interest. ${ }^{4}$ Unless otherwise stated, all election results and MP biodata used in this paper come from my aforementioned datasets. ${ }^{5}$

\footnotetext{
I am indebted to Jon Fraenkel for providing me with the PNG election results data, and to the Solomon Islands Electoral Commission and Parliamentary Library for their assistance with data.

4 Reflecting sensitivities associated with electoral politics, I have only named interviewees who provided explicit written permission for me to use their names.

Solomon Islands constituency-level election results data can be accessed at: https:// solomonislandselections.wordpress.com/. Polling station data, MP bio-data, and PNG election results data can be obtained by emailing the author. Accessed 26 November 2015. Most of the results data are also available in parliamentary Gazettes in the Solomon Islands Parliamentary Library.
} 


\section{Social and Political Context}

Solomon Islands and PNG are poor and poorly governed countries. In terms of GNI per capita in 2012 (adjusting for purchasing power parity) the two countries were the poorest in the Pacific and were in the bottom quartile of all countries globally. ${ }^{6}$ Similarly, the two countries are in the bottom quartile of all countries for government effectiveness as ranked by the World Bank. ${ }^{7}$ In both countries there is a clear link between poor political governance and poor governance more broadly: governments have tended to be unstable and have not fulfilled their legislative functions well, while senior political figures have frequently been associated with corruption. ${ }^{8}$

Both countries are extremely ethnically diverse: on the standard measure of linguistic diversity the two countries are the two most linguistically fragmented on earth, and both are home to thousands of clans. ${ }^{9}$ Set amidst weak states, social life is usually mediated by clan-based relational ties, community governance structures, and churches. ${ }^{10}$

Solomon Islands held its first post-independence election in 1980; PNG held its first election as an independent nation in 1977. Both countries have unicameral parliaments. Solomon Islands uses a single member district plurality electoral system and PNG used a similar system from independence until 2007, when it replaced it with a form of preferential voting. ${ }^{11}$ Elections in both countries have been characterized by high incumbent turnover rates and low winning candidate vote shares. Political parties exist in both countries but are weak. Parties' policy platforms tend to be non-specific and do not differ in obvious ideological ways. Voters rarely vote along party lines and the foremost driver of voter choices is candidate attributes, not candidate

6 World Bank, "World Databank," 2014, http://databank.worldbank.org/data/home.aspx. Accessed 17 April 2015. An alternate hardcopy location for the World Bank 2013 GNI data for Solomon Islands and Papua New Guinea is World Development Indicators 2015 (Washington, DC: World Bank, 2015), 27.

For country reports for Papua New Guinea and Solomon Islands, see World Bank, "Worldwide Governance Indicators,” 2013, http://www.govindicators.org. Accessed 17 April 2015.

8 Transform Aqorau, "Crisis in Solomon Islands: Foraging for New Directions," in Politics and State-Building in Solomon Islands, eds. Sinclair Dinnen and Stewart Firth (Canberra: Asia Pacific Press, 2008), 246-68; Ron May, "Disorderly Democracy: Political Turbulence and Institutional Reform in Papua New Guinea," State, Society and Governance in Melanesia Discussion Paper, 2003, no. 2 (Austalian National University, 2003).

$9 \quad$ Benjamin Reilly, Democracy and Diversity: Political Engineering in the Asia-Pacific (Oxford: Oxford University Press, 2006), 57.

10 Matthew Allen, Sinclair Dinnen, Daniel Evans, and Rebecca Monson, "Justice Delivered Locally: Systems, Challenges and Innovations in Solomon Islands," in Justice for the Poor (Washington, DC: The World Bank, 2013), 37; Michael Morgan, "Cultures of Dominance: Institutional and Cultural Influences on Parliamentary Politics in Melanesia," State, Society and Government in Melanesia Discussion Paper, 2005, no. 2 (2005), 4.

${ }_{11}$ Ace Electoral Knowledge Network, "Papua New Guinea," http://aceproject.org/epic-en/ CDCountry? country=PG. Accessed 10 October 2014; Jeffrey Steeves, "Solomon Islands," in Elections in Asia and the Pacific: a Data Handbook, eds. Dieter Nohlen, Florian Grotz, and Christof Hartmann (Oxford: Oxford University Press, 2001), 797. 
party affiliations. ${ }^{12}$ In both countries the most striking feature of voters' choices is a strong tendency to vote for candidates who they believe will provide them with private goods, or localized club goods, in exchange for their electoral support. ${ }^{13}$ As they vote in search of these forms of benefit, voters often vote along ethnic lines, voting for candidates with whom they share clan or similar relational ties, or a church affiliation. ${ }^{14}$

\section{The Explanation from Cultural Expectations}

Amongst academic studies devoted to explaining voter behaviour and its connection to political governance outcomes, the most common explanation offered hinges on the expectations that voters in the two countries hold of their leaders. These expectations are argued to be a product of a particular aspect of culture: the Big Man system of community governance the countries had in pre-colonial times, and which continues, to a degree, in the contemporary era.

The archetypal community Big Man earns, rather than inherits, the mantle of leadership, and governs over a community or communities, gaining status through deeds and dispensing material resources. ${ }^{15}$ Archetypes are elusive creatures, of course. In some communities in Solomon Islands, for example, leadership is inherited, not earned. ${ }^{16}$ And while community governance by Big Men is an element of both countries' cultures that has persisted from pre-colonial times into the present, context has changed, as have the roles of community leaders, at least to a degree. ${ }^{17}$ Nevertheless, as a loose characterization of the nature of community leadership in much of the two countries, the Big Man model is a tolerable enough generalization from which to derive an explanation of contemporary political culture.

12 Benjamin Reilly, "Party Politics in Papua New Guinea: A Deviant Case?" Pacific Affairs 72, no. 2 (1999): 225-246; Yaw Saffu, "Survey Evidence on Electoral Behavior in Papua New Guinea," in Eleksin: the 1987 national election in Papua New Guinea, ed. Michael Oliver (Port Moresby: University of Papua New Guinea, 1989), 15; Jeffrey Steeves, “Unbounded politics' and the Democratic Model in Solomon Islands: the 2010 National elections," Commonwealth EF Comparative Politics 49, no. 3 (2011): 342-358, 344.

${ }_{13}$ Oskar Kurer, "Why do Papua New Guinean Voters Opt for Clientelism? Democracy and Governance in a Frail State," Pacific Economic Bulletin 22, no. 1 (2007): 41; Terence Wood, "The Causes and Consequences of Local Voting in Solomon Islands," State, Society and Government in Melanesia in Brief, no. 17 (2013): 1-2.

14 Tarcisius Tara Kabutaulaka, "Pacific Islands Stakeholder Participation in Development: Solomon Islands," World Bank Pacific Islands Discussion Paper Series, no. 6 (1998): 22; Joseph Ketan, The Name Must Not Go Down: Political Competition and State-Society Relations in Mount Hagen, Papua New Guinea (Suva: University of the South Pacific, 2004); Terence Wood, "Ties that Unbind? Ethnic Identity, Social Rules and Electoral Politics in Solomon Islands" (PhD thesis, Australian National University, 2014).

15 Marshall D. Sahlins, "Poor Man, Rich Man, Big-man, Chief: Political Types in Melanesia and Polynesia," Comparative Studies in Society and History 5, no. 03 (1963): 285-303, 289.

16 John Naitoro, "The Politics of Development in 'Are 'Are Malaita," (Master's thesis, Otago University, 1993).

17 Allen et al., "Justice Delivered Locally," 9, 22, 31. 
As offered by scholars of the two countries, explanations of voter behaviour and political governance based on the Big Man model of local leadership proceed as follows: culture influences voter behaviour-and through this political governance-because voters think of politicians as Big Men and, as a result, hold expectations of them similar to those they hold of community Big Men. And so, just as Big Men are expected to deliver wealth and goods to their followers, so too are contemporary political leaders. ${ }^{18}$ Such expectations are typically argued to contribute to poor political governance because they reward MPs for disbursing resources to supporters foremost and do not incentivize MPs to govern the country as a whole well.

For example, writing of Solomon Islands Kabutaulaka explains that:

Voters have the same expectations of politicians today as the community had of the traditional Big-Man and most politicians react to these expectations as the village Big-Man would have-distributing wealth to members of the group and participating financially in nearly every community affair .... Unfortunately, it makes the politician vulnerable to bribery and other forms of corruption. ${ }^{19}$

Writing of PNG, Harris offers a similar explanation:

In most respects it is clear that what has happened is a transferal of the traditional big man system of gaining followers into the modern political system. ... Campaigning is based on those traditional redistributive relationships, with the leader providing resources to traditional supporters .... In return the supporters provide votes at the election. ${ }^{20}$

\section{As does Dinnen:}

The political leader builds prestige and following through the gifting of grants, development projects, infrastructural services, and other resources to constituencies based around personalised associations. State gifting has become a means for constituting political bigman-ship and is most apparent in the electoral context. ${ }^{21}$

Additional explanations of this kind can be found in studies spanning from

18 Some scholars (for example, Steeves, "Unbounded Politics," 344) have used the term "big man" when describing the relationship between politicians of elevated parliamentry stature and less powerful MPs; however, because my paper is focused on voter behaviour, and because Steeves' usage is descriptive, whereas I am focused on causal explanation, I have not engaged with this particular use of the term.

19 Kabutaulaka, "Pacific Islands Stakeholder Participation in Development: Solomon Islands," $28-29$.

20 Bruce Harris, "Papua New Guinea: A Nation in Waiting: The Dance of Traditional and Introduced Structures in a Putative State," World Bank Research Report (2007): 23-24.

${ }_{21}$ Sinclair Dinnen, Law and Order in a Weak State: Crime and Politics in Papua New Guinea (Honolulu: University of Hawai'i Press, 2001), 191, quoted in Kurer, "Why do Papua New Guinean voters opt for clientelism?" 44. 
some of the earliest work on PNG to some of the most recent and also in work on Solomon Islands. ${ }^{22}$

\title{
The Explanation from Rational Choice
}

The explanation from culture I have just described has been put forth by a number of the best scholars of PNG and Solomon Islands. Yet the explanation is not unchallenged. In particular, an alternative explanation has been ventured-one in which voter choices are driven by simple rational calculations alone, not expectations born of Big Man-style local leadership. This argument can be found in its most fully explicated form in the work of World Bank economist Tobias Haque on poor governance in Solomon Islands. ${ }^{23}$ The general thrust of his argument, which he offers as an explanation of voter behaviour and poor governance more generally, is that problems of governance in Solomon Islands are not products of Melanesian culture but stem from broadly rational responses on behalf of individual actors to the material incentives they face. In the case of voting, Haque's argument is that Solomon Islanders vote for personal or local benefits, not because of cultural conditioning, but because voting in this manner is the rational course of action in circumstances where voters' needs are immediate and where a weak state is unable to meet them. According to Haque this situation is compounded by a collective action dilemma in which voters who seek broader change cannot vote for it unless they have some cause to believe other voters are voting with similar motivations. Under such circumstances there is no need to appeal to culture to explain why voters vote the way they do. Instead, voters vote in search of local benefits because:

\begin{abstract}
In this context, it would take not just a very strong sense of national identity, but also an unusual preoccupation with long-term interests, a rarely overpowering altruism, and a similar faith in the altruism of others for any individual to base their voting behaviour on a candidate's national policy positions, rather than on the likelihood of a particular candidate providing direct benefits to the local community. ${ }^{24}$
\end{abstract}

Like proponents of the cultural expectations argument, Haque links voters' choices to poor political governance through the political incentives voters' choices create. However, for Haque voter behaviour itself is not a

22 For example, Steffen Dalsgaard, "All the Government's Men: State and Leadership in Papua New Guinea," (PhD thesis, University of Aarhus, 2009), 10; Thomas Harding, "The Rai Coast Open Electorate," in The Papua New Guinea Elections 1964, eds. David Bettison, Colin Hughes, and Paul van der Veur (Canberra: The Australian National University, 1965), 207; Morgan, "Cultures of Dominance," 4 .

23 Tobias Haque, "The Influence of Culture on Economic Development in Solomon Islands: A Political-Economy Perspective," State Society and Governance in Melanesia Discussion Paper, no. 1 (2012): $1-16$.

24 Haque, "The Influence of Culture on Economic Development in Solomon Islands," 5. 
product of culturally derived expectations, but rather a product of rational calculations.

While Haque offers the most fully formed explanation, other authors can be found advancing similar arguments. Writing of Solomon Islands, Cox argues against cultural explanations of politics, ${ }^{25}$ while in the case of PNG Reilly laments the tendency to over-attribute political behaviour to cultural factors rather than rational calculations ${ }^{26}$ Kurer similarly rejects (at least in part) culture-based explanations of voter behaviour in PNG, proposing game-theoretic alternatives involving imperfect information modelled on what are in effect rational actors. ${ }^{27}$

\section{Issues with these Explanations}

Both the explanation based on cultural expectations and the explanation from rational choice are plausible, yet neither turns out to be fully convincing.

\section{Cultural Expectations}

The first issue for explanations based on cultural expectations is that almost all of the observed features of the electoral politics of Solomon Islands and PNG that are claimed to be a direct legacy of Big Man models of traditional Melanesian governance can be found in many developing countries, including countries with very different cultural traditions and no recent history of Big Man-style local leadership. Voting in search of localized or personalized benefits—clientelism-is common in low-income countries, ${ }^{28}$ and the clientelism of Solomons and PNG is strikingly similar in its key features to that found elsewhere. Local brokers-influential community-level figures, tasked with winning candidates' votes-for example, are central to clientelism in both Solomon Islands and PNG, ${ }^{29}$ as they are elsewhere. ${ }^{30}$ And clientelism is coupled with significant vote buying in Solomon Islands and PNG,${ }^{31}$ as it is in other countries. ${ }^{32}$ Clearly, a history of Big Man-style traditional

25 John Cox, "Active citizenship or passive clientelism? Accountability and Development in Solomon Islands,” Development in Practice 19, no. 8 (2009): 964-980.

26 Benjamin Reilly, "Continuity and Change in Papua New Guinea Elections 1964-1997," in Maintaining Democracy: The 1997 Elections in Papua New Guinea, eds. Ron May and Ray Anere (Port Moresby: University of Papua New Guinea, 1997), 18.

27 Kurer, "Why do Papua New Guinean Voters Opt for Clientelism?" 47.

28 Susan Stokes, "Political Clientelism," in The Oxford Handbook of Political Science, ed. Robert Goodin (Oxford: Oxford University Press, 2009): 648-672, 668.

29 Colin Filer, "Steak and Grease': A Short History of Political Competition in Nuku," in The 1992 Papua New Guinea Elections: Change and Continuity in Electoral Politics, ed. Yaw Saffu (Canberra: Australian National University Department of Political and Social Change, 1996), 144-167; Ian Scales and Josephine Teakeni, "Election of Women in Solomon Islands the Case for a Local Governance Approach," The Journal of Pacific Studies 29, no. 1 (2006): 73.

30 Susan Stokes, Thad Dunning, Marcelo Nazareno, and Valeria Brusco, Brokers, Voters, and Clientelism (New York, NY: Cambridge University Press, 2013).

31 Douglas Marau, “The Devil's Night,” Solomon Star, 3 August 2010, http:/ /archives.pireport. 
governance is not a necessary condition for voters prioritizing personal or localized benefits over the national good. Nor does it appear that cultural expectations are required to explain other, related aspects of voter behaviour in the two countries. A propensity to vote for co-ethnics, for example, has also been well described in other developing countries. ${ }^{33}$

While the fact that key aspects of voter behaviour in Solomon Islands and PNG can be found in other parts of the world does not inevitably render the cultural expectations explanation false, it does weaken its plausibility. If much of what we are trying to explain is found elsewhere, why should we expect it to be the product of a form of traditional community governance found in Solomon Islands and PNG?

The argument that voters' choices in Solomon Islands and PNG are the product of expectations born of traditional models of community governance also struggles in that it is insufficient to explain a number of aspects of the countries' contemporary electoral politics. In important ways voters' choices and their relationship to MPs bear little semblance to relationships associated with traditional community governance. In particular, community Big Men reside in the villages they govern, or in instances come from neighbouring communities. ${ }^{34}$ However, in Solomon Islands and (possibly to a lesser extent) PNG, MPs are almost always members of urban elites, who often have familial linkages to the constituencies they represent but who do not actually live in them. In Solomon Islands, for example, David Day Pacha, the MP for South Guadalcanal, has lived in Honiara (the opposite side of the island from the constituency he represents) since he was a child and, unlike a Big Man-style local leader, prior to his entry into politics he was only very occasionally present in his home village in South Guadalcanal. ${ }^{35}$ Yet he has been able to win three consecutive elections there. Pacha is not unusual in this: Rick Hou, the MP for Small Malaita, to give another example, has lived almost all his adult life outside of Small Malaita and made the decision to stand as a candidate while living in Washington, DC. ${ }^{36}$

Moreover, Big Men almost always speak the same language and share other identity traits with their communities; yet this is not inevitably true of MPs in Solomon Islands or PNG. For example, ethnic Chinese businessman Thomas Chan won elections in the Solomon Islands constituency of West

org/archive/2010/August/08-06-fea1.htm; Bill Standish, “The Dynamics of Papua New Guinea's Democracy: an Essay," Pacific Economic Bulletin 22, no. 1 (2007): 135-157.

32 Stokes et al., Brokers, Voters, and Clientelism.

33 Kanchan Chandra, Why Ethnic Parties Succeed: Patronage and Ethnic Head Counts in India (Cambridge: Cambridge University Press, 2004); Daniel N. Posner, Institutions and Ethnic Politics in Africa (Cambridge: Cambridge University Press, 2005).

34 H. Ian Hogbin, "Social Advancement in Guadalcanal," Oceania 8 (1937): 289-305; Roger M Keesing, "Killers, Big Men, and Priests on Malaita: Reflections on a Melanesian Troika System," Ethnology 24, no. 4 (1985): 237-252; Sahlins, "Poor Man, Rich Man, Big-man, Chief."

35 David Day Pacha, interview by author, Honiara, voice recording, 2012.

36 Rick Hou, interview by author, Honiara, voice recording, 2012. 
Guadalcanal in 1997, and his son Laurie won again in 2001 and 2006. Possibly this occurred because the Chans bestowed gifts to constituents in a manner akin to that expected of traditional Big Men. But even so, if voter behaviour is trapped amongst expectations born of tradition, it seems unlikely that this would have been enough to overcome the fact that the Chans spoke a different language to their constituents, were of a different ethnic group and culture, and lived outside the constituency, particularly as their competitors in these elections, who were not Chinese, also attempted to win by buying votes and bestowing gifts. In a similar example of voters' willingness to be flexible in whom they support, a Vietnamese national, Namson Tran, was elected in 2010 in the Malaitan-dominated seat of West Honiara. There are also examples from PNG of Chinese- or Malaysian -born or descended MPs, including Perry Kwan and Robert Seeto $;^{37}$ and in 2012 Indian-born Sasindra Muthuvel was elected in PNG's West New Britain Province. At least seven European- or Australian-born expatriates have been elected to PNG's parliament since 2000 alone. For people supposedly trapped amongst traditional expectations of MPs, Solomon Islands and PNG voters are remarkably willing to throw their support behind aspiring politicians who appear nothing like their customary community leaders.

It also seems reasonable to anticipate that, if voters really thought of MPs as leaders akin to Big Men, actual village Big Men would be regularly elected to parliament. Yet, in Solomon Islands, the country for which there is the most complete dataset on the pre-electoral background of MPs, this is not common. There is an element of elevation to the pre-parliamentary lives of Solomon Island MPs in that they have much higher levels of education than their constituents, and often an elevated profile gained through employment in the cash economy, but available MP bio-data suggests that only in rare instances have MPs also been traditional community leaders. ${ }^{38}$ Similarly, discussing the Chuave constituency in the PNG highlands in 1988, Wayne Warry wrote that, while traditional leaders had at times been elected to parliament, "avenues to political power ... [were] becoming increasingly diverse." ${ }^{39}$

In sum, while some aspects of MP behaviour and of the MP-voter relationship appear analogous to traditional villager-Big Man relationships, there is also much which is not-a fact which does not fit easily alongside explanations of voter behaviour based on culturally determined expectations.

37 Hank Nelson, "The Chinese in Papua New Guinea," State, Society and Governance in Melanesia Discussion Paper, no. 3 (2007).

38 Jack Corbett and Terence Wood, "Profiling Politicians in Solomon Islands: Professionalisation of a Political Elite?” Australian Journal of Political Science 48, no. 3 (2013): 329.

39 Wayne Warry, Chuave Politics: Changing Patterns of Leadership in the Papua New Guinea Highlands (Canberra: Australian National University, 1987), 9. 


\section{Rational Choice}

Just as closer analysis provides examples of inconsistencies with the cultural expectations explanation, similar analysis also reveals electoral features not easily explained by models of rational voters acting completely independently of at least some aspects of the cultural context of Solomon Islands and PNG. In this section I demonstrate this by detailing two features of the countries' electoral politics that do not fit easily with simple rational choice explanations of voter behaviour: high effective numbers of candidates and low numbers of women MPs. I also use patterns of voting outcomes within one Solomon Islands constituency, West 'Are Are, to provide a more specific example of a case that simple rational voter models cannot explain on their own.

\section{Candidate numbers}

A major problem for rational choice explanations of politics in Solomon Islands and PNG comes in the form of these countries' divergence from the predictions of Duverger's law. Duverger's law is one of the central axioms of political science, and posits that single-member district plurality electoral systems of the sort used in PNG from 1977 to 2002, and still used in Solomon Islands, will produce constituency-level contests that tend towards twocandidate competition over time (or, more technically, a tendency towards competitions where the Effective Number of Candidates [ENC] converges to two) ${ }^{40}$ This tendency is theorized to be a product of voters strategically abandoning favourite candidates for less favoured candidates whom they calculate as being more likely to win. ${ }^{41}$ Importantly, because in single-member district plurality electoral systems a vote for a candidate who is unlikely to win is, in effect, a wasted vote, such strategic abandonment is what rational voters ought to do in most circumstances.

Adding credence to the theoretical underpinnings of Duverger's law is a body of international evidence showing electoral convergence of the sort predicted by the law. ${ }^{42}$ However, in neither Solomon Islands nor PNG do we see average ENC values close to two. Figure 1 shows the effective number of candidates for Solomon Islands, averaged across all constituencies for each post-independence election. Figure 1 also plots the same feature for those elections (1977-2002) in which PNG used a single-member district plurality voting system. The straight horizontal line in the figure takes the value of

40 ENC is calculated as 1 divided by the sum of all candidates' squared vote-shares. For further information see: Gary Cox, Making Votes Count (Cambridge: Cambridge University Press, 1997), 29.

41 Maurice Duverger, Political parties: their Organization and Activity in the Modern State (London: Methuen, 1954). While Duverger's law is often applied to numbers of parties in national competition it was first theorized with respect to candidate numbers at the constituency level and has been applied this way in other recent work. For example, Matthew Singer and Laura Stephenson, "The Political Context and Duverger's Theory: Evidence at the District Level," Electoral Studies 28, no. 3 (2009): 480-91.

42 Singer and Stephenson, "The Political Context and Duverger's Theory," 481. 
two: the value the countries' average ENCs ought to take if result patterns conformed to Duverger's law.

\section{Figure 1}

Effective Numbers of Candidates across Time, Solomon Islands and PNG

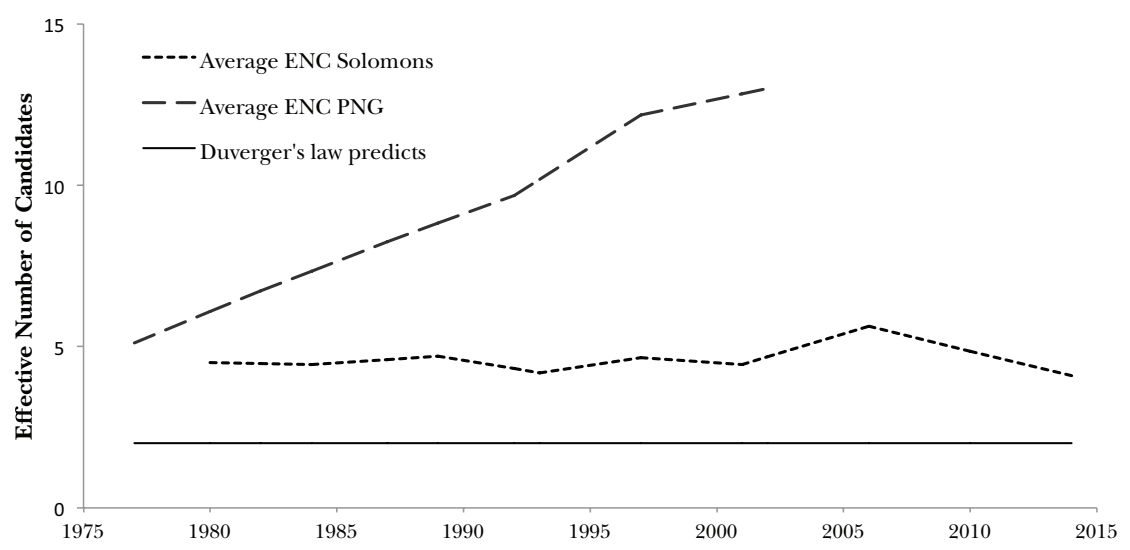

Source: Author's Papua New Guinea and Solomon Islands election results databases.

In Solomon Islands' case the ENC has averaged about four, twice what Duverger's law would predict, and has remained relatively constant. In PNG the average ENC increased from slightly over 5 to 13 between 1977 and 2002. To be clear, such deviations are striking, but they are not inexplicable. For example, one explanation for high candidate numbers which has been offered is the ethnic diversity of the two countries and a propensity for voters to vote for co-ethnics. ${ }^{43}$ Yet, while explanations of this form are plausible, on their own they are not sufficient to resolve the issues that divergence from Duverger's law raise for proponents of rational choice explanations. People may be voting ethnically in the two countries but why are they doing this? What are their reasons for voting for co-ethnics?

\section{Women candidates}

As in most countries, in Solomon Islands and PNG women make up approximately half the population. Yet they comprise a much smaller share of the two countries' parliaments. As of 2014, PNG had only three women MPs while Solomon Islands had but one. Figure 2 shows women MPs as a percentage of total MPs for both countries from 1997 to 2014.

While women are under-represented in parliaments the world over, the

43 Reilly, Democracy and Diversity: Political Engineering in the Asia-Pacific, 50. 
Figure 2

Women MPs as a Percentage of all MPs, Solomon Islands and PNG

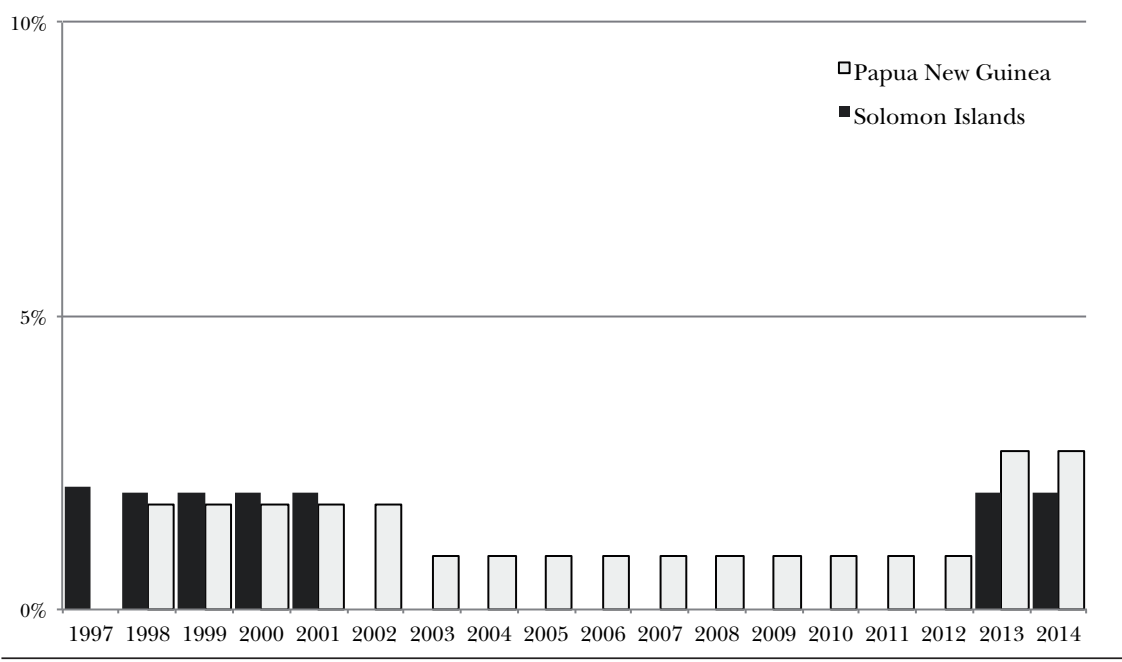

Source: data are from the International Parliamentary Union's dataset. Online at http://ipu.org/wmn-e/classif-arc.htm

situation is particularly egregious in Solomon Islands and PNG. Globally, at the start of 2014 women comprised on average 20 percent of the world's parliaments or equivalent bodies. In PNG and Solomon Islands in that year the same statistic was an order of magnitude lower. ${ }^{44}$ This is hard to square with a simple model of rational voters in which cultural context is playing no role in shaping electoral outcomes. One might possibly explain the outcome by positing that women are less well suited to political office, and as a result voters, perfectly rationally, choose to vote for men. However, such a theory would struggle to explain why voters in other parts of the world are much more likely to vote for women. Moreover, available cross-country evidence actually suggests the opposite: performance in a range of key development indicators tends on average to be better where there are more women serving in parliaments. ${ }^{45}$ As before, the point here is not that low numbers of women MPs in Solomon Islands and PNG is inexplicable, but rather that it is hard to explain the outlier nature of these two countries using simple rational choice models of voter behaviour on their own.

44 Data used here come from the International Parliamentary Union's women parliamentarians dataset: http://ipu.org/english/home.htm. Under the "Resources" menu item, select "Women in Parliaments Data," then click on "archive of statistical data," then click on "1 January 2014." Accessed 26 November 2015.

45 David Dollar, Raymond Fisman and Roberta Gatti, "Are Women Really the 'Fairer' Sex? Corruption and Women in Government," Journal of Economic Behavior E Organization 46 (2001): 423-429; Dinuk Jayasuriya and Paul Burke, "Female Parliamentarians and Economic Growth: Evidence from a Large Panel," Development Policy Centre Discussion Paper, no. 18 (2012). 


\section{Results in West 'Are Are}

One final example of an electoral feature that simple rational choice models of voter behaviour struggle to explain comes in the form of patterns of election results found in the constituency of West 'Are Are in Solomon Islands. Figure 3 shows election results by polling station for the constituency in the 2010 general election. Each bar is a polling station, each block within the bar represents the number of votes won by an individual candidate in that polling station. Polling stations are arranged to reflect location: the left-most polling station in the chart is the northern-most, the right-most the furthest south. The constituency is also divided into two wards: the northern ward of Tai and the southern ward of Mareho.

Examination of the results reveals a clear difference: in polling stations in Tai votes are fragmented amongst a greater number of candidates than they are in polling stations in the Mareho ward. On the standard measure of fragmentation, the Herfindahl-Hirschman index, under which zero is complete fragmentation and one is perfect homogeneity, the average score of candidate fragmentation at the polling-station level in Tai is 0.21 , while in Mareho it is 0.49 (a difference that is statistically significant at the 1 percent level when a two-tailed t-test is run). ${ }^{46}$

For some reason voting patterns in the Mareho ward of the constituency are much less fragmented than in Tai. In Tai, numerous candidates win small slices of support at each polling station (with the occasional bigger candidate winning a larger share of support.) In Mareho only a few candidates win meaningful numbers of votes, but those that do win, win larger shares of the votes on offer at each polling station. There is no obvious explanation for this difference. Formal electoral rules and procedures are, of course, the same in both parts of the constituency. And the stakes-electing the constituency's one MP-are also the same. Moreover, the result is not an anomaly: results for 2006 show a similar pattern. The result is not a product of geographical differences; while there are a few more inland villages in Tai, both wards contain both inland and coastal villages, and villages are not, on average, further apart in Tai, or more isolated. The same language is spoken throughout the constituency. The difference is also not a product of polling stations in the north serving more villages than their southern equivalents: on average individual polling stations serve similar numbers of villages in both wards. ${ }^{47}$

46 The Herfindahl-Hirschman index for any given polling station is calculated as the sum of the squared vote shares won by each candidate at the polling station.

47 To test this formally I used 2010 data, with polling stations as the unit of analysis, and regressed polling station fragmentation against a dummy variable capturing the ward the polling station was in, while also controlling for a fragmentation measure based on electoral roll data which reflected the extent to which each individual polling station was spread across villages. Confirming the t-test result reported above, the ward dummy was statistically significant at the 1 percent level, while the variable capturing the extent to which polling stations were fragmented across villages was not correlated with polling station fragmentation of candidate support. 
Is Culture the Cause?

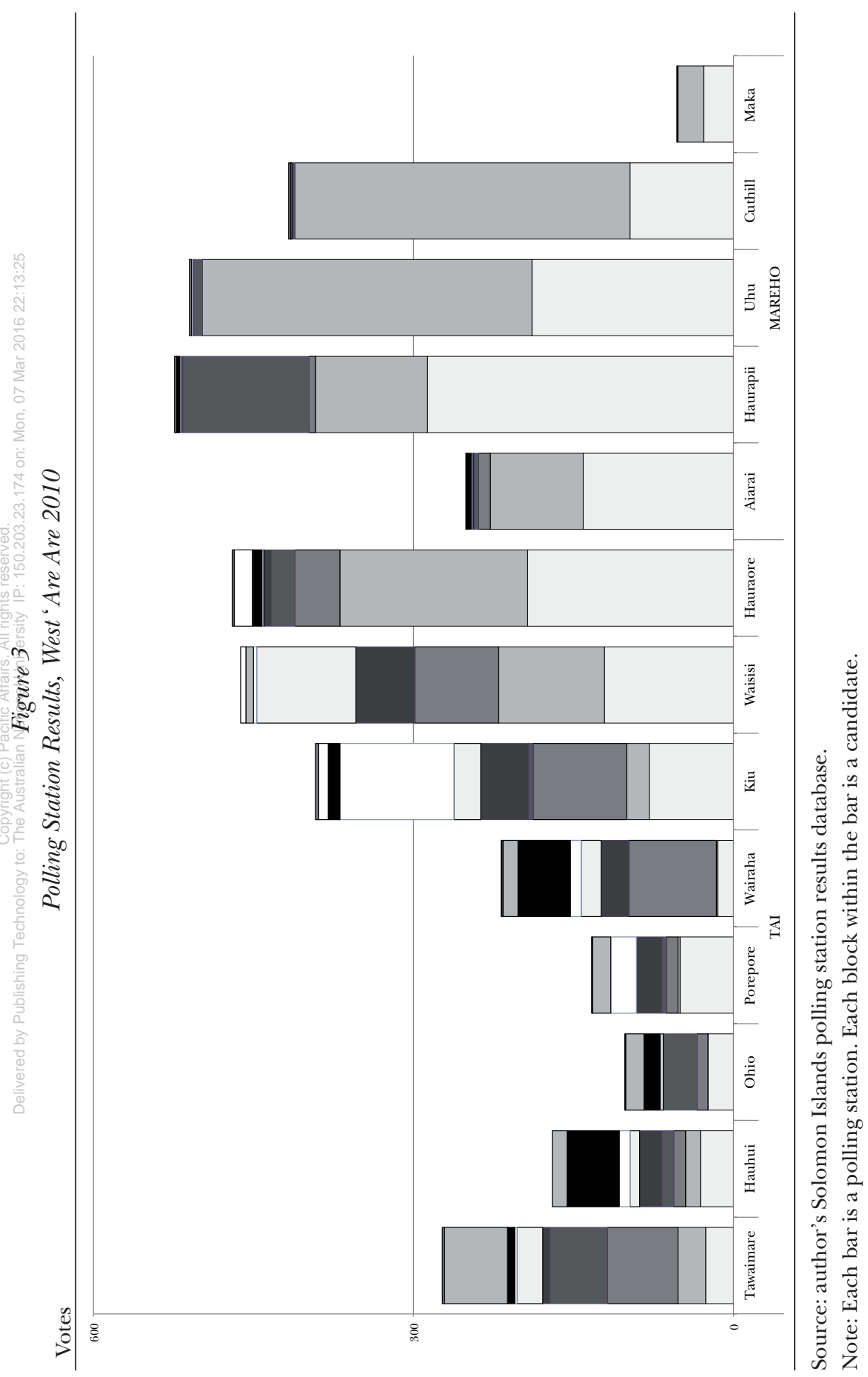


Once again, an electoral results pattern-this one localized-is hard to explain through a schema in which all that is on offer is rational voters responding to their preferences, and incentives generated by a formal electoral process. What reason would otherwise rational voters have to vote in blocs in the south, while scattering their ballots in a much more fragmented manner in the north?

\title{
Bringing Culture Back In
}

Neither of the two electoral features (high candidate numbers and poor female candidate performance), nor the case of West 'Are Are, are easy to explain using simple rational choice models of voting on their own. Yet each is explicable if one is willing to allow a role for the cultural contexts of Solomon Islands and PNG and, specifically, a role for informal institutions associated with the cultures of the countries under study.

\section{West 'Are Are, local leaders, and group unity}

Former candidates from West 'Are Are provided me with the explanation for the variation in the constituencies' polling station results patterns. In the Tai ward communities are governed by community-selected leaders whose sway over community members is comparatively weak. However, in Mareho ward, communities are governed by leaders who inherit their titles and who exert considerable control over village life and villagers' decisions. ${ }^{48}$ In the Tai ward votes are won one voter at a time; in Mareho they are won one chief at a time. If a chief can be won over he can, by edict, deliver the community's votes, or a large share of them, to the candidate. Alice Pollard, who stood unsuccessfully as a candidate in West 'Are Are in 2006 and 2014, stated that voters in the Mareho ward

\begin{abstract}
listen to this person who came to be the chief because they were the first born son in the tribe, and he becomes very, very powerful ... . So once a chief from the Ha'arahana house of chiefs [the house of chiefs which covers Mareho] says 'this person is our candidate' then voters have to follow his instruction. ${ }^{49}$
\end{abstract}

In a similar vein, Lawrence Hunumeme, whose village is on the border of the two wards, and who stood as a candidate in 1997, 2001, and 2006, explained the rules of punishment for voters who disobeyed chiefs in Mareho: "[I]f you don't vote for who the chief says you will be told to provide compensation after the election period ... usually compensation would cost

48 Naitoro, "The Politics of Development in "Are 'Are Malaita," 11; Alice Pollard, "Painaha: Gender and Leadership in 'Are "Are Society, the South Sea Evangelical Church and Parliamentary Leadership-Solomon Islands," (PhD thesis, Victoria University, 2006), 82.

49 Alice Pollard, interview by author, Honiara, voice recording, 2011. 
a pig and some shell money." He then added that, "from my village downwards [the Tai ward], the chief system is not as strong ... and therefore you don't pay any compensation." ${ }^{50}$

This explanation is not fundamentally at odds with a rational choice model of voters. However, a difference in social rules-informal institutionsbetween the two parts of the constituency leads to different voter behaviour. In the northern part of the constituency, rules do not compel voters to vote as they are told to vote by community leaders, and voters decide on their own who they believe most likely to deliver the sorts of private or club goods they desire. In the south, however, because of informal institutions that afford chiefs decision-making power, and because of rules which can be used to punish those who disobey, voters vote as they are told. Voters' calculations remain rational enough. However, informal institutions play a crucial role in shaping the context within which they make their choices.

While West 'Are Are provides an illustrative case, there are other examples of the impact of local-level informal institutions on voting patterns and voter choices in Solomon Islands and PNG. Writing of Hagen in PNG's Western Highlands, Joseph Ketan describes the consequences faced by voters who transgress rules of clan bloc voting, stating that: "Banishment is perhaps the harshest penalty for members who do not conform to clan policies regarding elections ... . " ${ }^{51}$ Similarly, writing of voters in Enga province (also in the PNG highlands) Gibbs describes voters compelled to vote along clan lines although he also notes that such compulsion varies.

Clan unity is important, but not easy to maintain when people live along the main highway and have easier access to services. There, people have more freedom to decide for themselves and the clan has less influence over its members. ${ }^{52}$

In addition to the intra-provincial variation described by Gibbs in Enga, there is also considerable inter-provincial variation to be found in PNG. For example, after analyzing election outcomes in the predominantly lowland (in terms of population) constituency of Angoram, May found only limited evidence of voting along clan lines and found that major candidates obtained support from across the constituency, which suggests that informal institutions compelling within-group loyalty are comparatively weak in much of Angoram..$^{53}$

Likewise, in Solomon Islands the ability of clan and community leaders

50 Lawrence Hunumeme, interview by author, Honiara, voice recording, 2012.

51 Ketan, The Name Must Not Go Down, 246.

52 Phillip Gibbs, Nicole Haley, and Abby Mcleod, "Politicking and Voting in the Highlands: The 2002 Papua New Guinea National Elections," State, Society and Governance in Melanesia Discussion Paper, no. 1 (2004), 5 .

53 Ron May, "The 'Clan Vote' in Papua New Guinea Open Electorates: Data from Angoram," The Journal of Pacific Studies 29, no. 1 (2006): 108-130. 
to influence voters varies, not only within constituencies as in the West 'Are Are case, but also between different parts of the country. There has also been change in the strength of informal institutions over time. For example, speaking of voters' freedom to choose, a former provincial MP from Isabel province stated that, in the past, "when the leader of a tribe said "we will vote for this man', everyone had to vote for this man ... . Now, even if the chief says who to vote for, people vote as they choose." 54

Such change still fits with rational choice models of voter behaviour if an element of culture-specifically informal institutions that do, or do not, mandate conformity with leaders' choices-is added into the equation. Such institutions vary across different parts of the two countries under study and they change over time and, reflecting this, the electoral power of community leaders also varies considerably.

\section{Female candidates, gender norms, and wealth}

The intersection of informal institutions and voters' choices is also where the explanation for the poor performance of female candidates in PNG and Solomon Islands can be found. In both countries money plays a role in campaign success. Large amounts are exchanged either to purchase the support of voters or local leaders, or as a signal, suggesting the candidate doing the giving is the sort of person who will dispense ongoing largesse if they are elected. ${ }^{55}$ Similarly, in both countries, as in most clientelist polities, obtaining local brokers or interlocutors, who help deliver voters' support in communities, is an important element of electoral success. In both these aspects of electoral competition women are at a disadvantage. Owing to social norms, men are more likely than women to receive an education and more likely to engage in the cash economy, and major business figures tend to be men. At the time of the 2009 Solomon Islands census only 28 percent of the 55,500 Solomon Islanders working in the formal economy were women, ${ }^{56}$ and women working in the formal sector have tended to work less well paid positions ${ }^{57}$ Similarly, preliminary analysis of data from the 2009-2010 PNG Household Income and Expenditure Survey suggests that men are almost twice as likely to work for wages as women. ${ }^{58}$ For these reasons the best-

54 Former Isabel Province provincial MP, interviewed by author, Honiara, voice recording, 2012.

55 Bill Standish, "The Dynamics of Papua New Guinea's Democracy," 140; Terence Wood, "Elections and Electoral Quality in Solomon Islands," State, Society and Government in Melanesia in Brief, no. 40 (2014), 1.

56 Solomon Islands National Statistics Office, Report on 2009 Population Ẽ Housing Census: Basic Tables and Census Description, vol. 1 (Honiara: Statistics Office, Ministry of Finance, 2013), vi.

57 Elise Huffer, "Desk Review of the Factors Which Enable and Constrain the Advancement of Women's Political Representation in Forum Island Countries," in A Woman's Place is in the House - the House of Parliament. Research to Advance Women's Political Representation in Forum Island Countries: A Regional Study Presented in Five Reports, ed. by Elise Huffer (Suva: Pacific Islands Forum Secretariat, 2006), 37.

58 Government of Papua New Guinea, "Papua New Guinea Country Gender Assessment 2011-2012," (Government of PNG: Port Moresby, 2012), 5. 
resourced candidates are usually men, and because vote buying is typically an electoral necessity, an important source of electoral advantage is gendered. Similarly, informal institutions that mean that community leaders are predominantly male, coupled with norms that make it unusual for male leaders to work for female candidates, make it harder for female candidates to obtain local leaders as brokers, which further disadvantages female candidates. ${ }^{59}$

As before, this is not at odds with explanations of electoral politics based on rational voters. It will often be perfectly rational for a voter concerned foremost with their own welfare, or that of their family or community, to support a well-resourced candidate who has provided evidence of their generosity in the form of gifts. And trust or fear of consequences also provide good reasons for a voter to follow the directives of a local leader whose support a candidate has obtained. However, here again, informal institutions matter and have gifted men advantages in access to material resources and to influential leaders. Rational choice models are incomplete if they do not reflect this.

\section{Candidate numbers and electoral coordination}

An understanding of the interaction between informal institutions and voter behaviour is also required if we are to successfully explain high effective numbers of candidates in PNG and Solomon Islands. Of particular importance in this instance is the role of informal institutions in influencing electoral coordination and collective action. In electoral competition, where more votes means a greater chance of victory, the ability to coordinate-that is, the ability to unite the support of a sizeable group of people behind a particular candidate-is important, not only for candidates, but also for voters in deciding which candidates have a chance of winning and upon which candidates support would be wasted. In many countries political parties and/or associated social movements provide such tools of coordination. ${ }^{60}$ Yet in both Solomon Islands and PNG parties are very weak, and both countries lack large-scale social movements.

In lieu of parties and social movements as tools of electoral coordination, clans, communities, and churches can offer a form of structure which, to a degree, can coordinate politics. Indeed, in both countries there are instances of these groups coordinating politics and reducing electoral fragmentation effectively within constituencies. The Christian Fellowship Church (CFC) in Solomon Islands has been, until a recent church split, a good example of this. Prior to the split, in CFC villages informal church rules afforded the

$59 \quad$ Scales and Teakeni, "Election of Women in Solomon Islands the Case for a Local Governance Approach," 74; Terence Wood, "Why Can't Women Win? Impediments to Female Electoral Success in Solomon Islands," Centre for Democratic Institutions Discussion Paper, no. 01 (2014): 10-11.

${ }^{60}$ Francis Fukuyama, "Democracy and the Quality of the State," Journal of Democracy 24, no. 4 (2013) 
church decision-making power over most aspects of life, ${ }^{61}$ and church members were only able to stand as candidates if approved by the church. Furthermore, as a resident from a majority CFC constituency explained to me, informal institutions that stipulated church members must obey the diktats of church leaders meant that if CFC voters were "found to have voted for another candidate their lives could be made difficult. ... So even if they don't want to vote for the candidate from their church, they have to." 62

Although CFC adherents disputed allegations of coercion when I interviewed them, they still acknowledged the importance of the church. For example, Nelson Boso, a former MP for West New Georgia constituency, and a CFC adherent, suggested it was voter and village leader gratitude that gave the church its power, while at the same time conceding the church's power was important. When I asked him whether he needed brokers to help him win votes he told me this was the case in some parts of the constituency but not in church areas: "[o]nce you get the backing of the church you don't really need agents or to spend money." ${ }^{63}$ Election data reflect the church's power of electoral coordination: until the split it was exceptionally rare for more than one CFC candidate to stand in a constituency, and there was a strong correlation between the CFC's population share at the constituency level and the vote share won by CFC candidates. ${ }^{64}$

The CFC is not the only example from the two countries of a church facilitating electoral coordination. In his description of PNG Highlands electoral politics, Warry describes a degree of coordination within the Seventh Day Adventist Church. ${ }^{65}$ Similarly, in the Solomon Islands constituency of Small Malaita a church pastor from the South Seas Evangelical Church explained how, within the constituency in 2010, a more subtle norm of cooperation saw church pastors agreeing to unite behind a candidate (Rick Hou, who won the election) and the importance of this.

\begin{abstract}
Normally during the campaign most of us pastors work together to share whether a candidate is good. We share information with the community. Pastors play a big role during that time [the 2010 campaign]. Because they look after their congregations people are likely to listen to them. ${ }^{66}$
\end{abstract}

Churches are not the only entities bound by informal institutions that can facilitate electoral coordination. As discussed above, communities and clan

61 Allen et al., "Justice Delivered Locally," 63.

62 North New Georgia resident, interview by author, Honiara, voice recording, 2012. For an additional description of CFC voting see: W.K. Talasasa, "Submission to the Solomon Islands Constituency Boundaries Report," in Solomon Islands Constituency Boundaries Report, eds. Gordon Siama et al. (Honiara: Solomon Islands National Parliament, 1979), 55-56.

63 Nelson Boso, interview by author, Munda, voice recording, 2012.

64 Wood, "Ties that Unbind?" 209-215. The only instance I am aware of where more than one CFC candidate stood in the same constituency was in West New Georgia in 2010; however, the church was already in the process of splitting at that point.

65 Warry, "Chuave Politics," 250.

66 SSEC pastor, interview by author, Small Malaita Constituency, voice recording, 2012. 
groups can also play important roles in coordinating electoral collective action. However, there are a number of reasons why such groups fail to curb candidate proliferation.

The first of these is simply that the groups that contain sufficiently strong rules to be able to practice within-group coordination are often small: as noted in the introduction, there are thousands of clans and villages across the two countries, and often numerous clan groups and communities in any individual constituency. Some churches are larger (although the CFC only makes up about 3 percent of Solomon Islands' population ${ }^{67}$ ); however, the cooperation they engender tends to be localized and facilitated through personal networks within constituencies.

Also, within-group coordination is not guaranteed. While there are instances of group coordination enabled by informal institutions such as those I have just described, often groups that might be expected to facilitate electoral cooperation lack the sorts of norms necessary to promote electoral cooperation and, as a result, fail in this area. When I interviewed a senior Anglican bishop from the Small Malaita constituency (where Anglicans were the largest denomination) he lamented that, "there are quite a few of us Anglicans and if we united behind one candidate we would always win, but we do not do it." ${ }^{68}$ Even in groups that can coordinate at least some of the time, such as the PNG Highlands clans described earlier, perfect coordination is rare, and larger groups often fragment, meaning more candidates and the loss of elections which could have been won. ${ }^{69}$

To reiterate, none of this is at odds with rational voting. It is reasonable to follow the leaders of one's group when punishment will otherwise occur. It is reasonable to follow the advice of trusted leaders. It is reasonable for leaders and group members to try and coordinate support behind one candidate to increase the chances of winning, just as it is reasonable enough to expect that this will not always work when rules within groups are not overwhelmingly strong or when groups are too small. However, informal institutions are important in understanding the link between voter behaviour and electoral outcomes. Specifically, informal institutions assist in facilitating electoral coordination (be this through enabling compulsion, or fostering cooperation). And in Solomon Islands and Papua New Guinea the entities that possess enabling social rules are often too small to produce large-scale electoral cohesion and through this reduce candidate numbers. Or, in other instances, the rules that might enable cohesion are too weak and fragmentation occurs.

67 Solomon Islands National Statistics Office, "Report on 2009 Population \& Housing Census," 53.

68 The Right Reverend Alfred Hou, interview by author, Small Malaita, voice recording, 2012.

69 John Burton, "Tribal Structure and Rural Ballot Box Counts in Hagen Open," in Eleksin: The 1987 National Election in Papua New Guinea, ed. Michael Oliver (Port Moresby: University of Papua New Guinea, 1989), 256; Gibbs, "Politicking and Voting in the Highlands," 5. 
The challenges of large-scale collective action also help explain the pervasive clientelism of electoral politics in Solomon Islands and PNG. As noted by Haque in his rational choice explanation of voter behaviour, voters face a collective action dilemma: there is no point in choosing to vote in search of a better governed state unless voters can be sure many of their compatriots are also doing so. And, above and beyond fragmentation within electorates, because Solomon Islands and PNG lack entities, such as parties and social movements, that can facilitate large-scale collective action (groups which, themselves, need to be bound by norms of cooperation), voters are denied the ability to vote for better governance whilst confident their fellow citizens are also doing this. As a result voters vote in search of local benefits and politicians respond in kind.

\section{Conclusion}

An understanding of culture is necessary if we are to fully explain voter behaviour and its link to political governance in Solomon Islands and PNG. Yet culture's role in causing the politics seen in the two countries is not that normally offered by scholars of Melanesia. It is not voters trapped within tradition, thinking of politicians as they do of Big Men, that gives the two countries the politics they possess. Instead it is voters making broadly rational choices in search of material ends, who are at the same time being influenced by informal institutions. Results patterns vary within and between constituencies because of variations in informal institutions and the power they afford particular local actors. Women are disadvantaged because norms associated with access to paid work mean they have fewer resources to campaign with, and because they want for access to influential local supporters. Candidate numbers are high because social rules that might facilitate electoral coordination are usually weak, especially outside of comparatively small groups.

Culture and reasoned choices are not competitors in explaining voter behaviour in Solomon Islands and PNG. Rather, the two are complements. Yet, this is only the case if culture's impact is properly understood. Culture's impact is not a product of voters' beliefs about Big Men and related expectations that voters hold of MPs, but rather it is a product of informal institutions that shape who and what voters can vote for-and with this much of the nature of political governance.

Australian National University, September, 2015 